\title{
Processing and properties of hollow glass microsphere particulate-filled PA2200 composites produced by selective laser sintering
}

\author{
Dong $\mathrm{Ye}^{1, *}$, Lihua $\mathrm{Yu}^{1}$, Gaoyan $\mathrm{Hou}^{1}$, and Hong $\mathrm{Zhu}^{1}$ \\ ${ }^{1}$ Wuhan Polytechnic, School of Electrical and Mechanical Engineering, 430081, Wuhan, Hubei Province, China
}

\begin{abstract}
Selective laser sintering (SLS) to prepare composites by adding filler into polymer is an effective method to save costs and reinforce the sintered parts. This article investigated the fabrication of PA2200 composites filled with different volume fractions of hollow glass microsphere (HGM) by SLS. HGM was prepared by silane coupling agent surface treatment. The particle size distribution, microstructure, thermal and mechanical properties of PA2200/HGM composites were studied by scanning electron microscopy (SEM), differential scanning calorimetry (DSC) and tensile experiment. The results indicated that the density of the composite was significantly reduced compared to the neat PA2200 and the density decreased with the HGMs content increasing. HGM improved the warping deformation in the process of sintering. The tensile modulus increased while tensile strength and elongation at break decreased as a function of HGM volume fraction in a certain range. This work indicated that thermal properties and tensile properties of polyamide-matrix composites can be reinforced by adjusting HGM content, and PA2200/HGM composite powder is a good material for SLS with less density and lower cost.
\end{abstract}

\section{Introduction}

Selective laser sintering (SLS) is an additive manufacturing technique which uses a laser beam to locally melt polymer powder to build products in a layer by layer fashion. SLS has been widely used for its unique advantages in the diversification of the SLS material, material saving, sintering without support, high intensity parts and rapid metal parts manufacturing[1].

Polyamides are one of the most important engineering thermoplastics in electronic, automobile, packaging, textiles and consumer applications owing to their excellent mechanical properties. During the past years, laser sintering of polyamide (PA) has developed and grown into a viable prototyping tool and production method for small series production of high strength functional polymer parts[2,3]. At present, the common polyamide powder materials in the market mainly include PA6, PA11, PA12, etc. PA2200 is a special multipurpose material based on polyamide PA12 that developed for Eosint-p series rapid prototyping equipment by EOS $\mathrm{GmbH}$. Its typical application is the functional prototype after high precision machining and polishing with high cost.

However, limitations in the mechanical properties level, the low heat deflection temperature, high water absorption and dimensional instability of the pure polyamides have prevented their applications to form structural components. Hence, polyamide composites, containing traditional fillers, have been studied extensively for decades and many works have been published towards last 30 years. For reasons of economy and also to favorably obtain materials with enhanced properties, glass fibers are commonly added to polyamide. Despite the outstanding features of polyamide adding glass fibers, their poor fluidity, high shrinkage and serious back warping are not adequate to meet expectations in many industrial applications[4].

Hollow glass microsphere (HGM) mainly composed of borosilicate glass is an important inorganic filler, which has low density, high temperature resistance, good fluidity, heat insulation and good thermal stability. Through surface modification, HGB are applied to produce the composites, resulting in consequently improved properties. The improvements are in physical properties, such as tensile strength, elasticity modulus, the dimensional stability, heat distortion temperature and low density [5-7].

More previous studies on the effect of HGM in polyamide composites have been carried out. DING et al. [8] investigated the effect of HGM on the mechanical properties and melt viscosity of nylon 6 parts produced on SLS. The results showed an increase in tensile strength and impact toughness resulted in an increase of the HGM content when the HGM content is less than $20 \mathrm{wt} \%$. And the melt viscosity also decreases, which was shown to have a positive effect on the melt viscosity and the mechanical properties of sintered parts. Sun et al. [9] confirmed that there is a positive relation between the small particle size of HGM filler and the part properties of nylon composite. Wang et al. [10] studied the tensile strength, tensile modulus, elongation at break, sintering

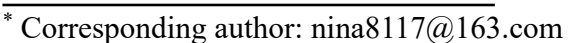


properties and part density of PA12/HGM composite parts. The experiment has showed that the PA12/HGM composite had an excellent performance in spreading powder, and HGB could reinforce the mechanical propertied and the warping and shrinkage deformation of PA12.

In this investigation, to develop composite materials with light weight, low cost and excellent performance, HGB prepared by silane coupling agent surface treatment as fillers by weight ratio were added to PA2200. The influence of the addition of these fillers on the tensile strength, modulus, elongation at break and thermal properties of PA2200/HGM composites were examined. Finally, the effect of adding HGM was investigated.

\section{Experimental procedure}

\subsection{Materials and Processing}

The matrix material PA2200 with the average particle size of $60 \mu \mathrm{m}$ and the white appearance was obtained from EOS $\mathrm{GmbH}$ in Germany. And the mixing ratio of new and old powder is 1:1. Filler additives, hollow glass microsphere was surface treated with silane coupling agent supplied by The Minnesota Mining and Manufacturing(3M) Company in USA. As an inorganic material, hollow glass microspheres have no polarity and poor compatibility with PA2200, thus the mechanical properties of sintered parts of PA2200 and untreated HGM composite will greatly decrease. Silane coupling agent is soluble in water and plays a coupling role that bridging between inorganic and polymer. Therefore, in order to improve the interface bonding between HGM and polyamide, silane coupling agent is commonly used to modify HGM [11,12].

After drying, hollow glass microspheres were sieved

Table 1. Process parameters used in SLS of the samples

\begin{tabular}{|c|c|c|c|c|c|c|c|}
\hline Material & $\begin{array}{c}\text { Filler } \\
\text { content } \\
\mathbf{( \% )}\end{array}$ & $\begin{array}{c}\text { Laser } \\
\text { beam } \\
(\mathbf{W})\end{array}$ & $\begin{array}{c}\text { Building chamber } \\
\text { temperature } \\
\left({ }^{\circ} \mathrm{C}\right)\end{array}$ & $\begin{array}{c}\text { Scan } \\
\text { spacing } \\
(\mathbf{m m})\end{array}$ & $\begin{array}{c}\text { Scan } \\
\text { speed } \\
(\mathbf{m m} / \mathbf{s})\end{array}$ & $\begin{array}{c}\text { Sintering layer } \\
\text { thickness } \\
(\mathbf{m m})\end{array}$ & $\begin{array}{c}\text { Energy density } \\
(\mathbf{E D}) \\
\left(\mathbf{J} / \mathbf{m m}^{2}\right)\end{array}$ \\
\hline PA2200 & 0 & 40 & 170 & 0.3 & 3000 & 0.12 & 0.04 \\
\hline PH-1 & 15 & 40 & 176 & 0.25 & 3000 & 0.12 & 0.053 \\
\hline PH-2 & 30 & 40 & 176 & 0.25 & 2500 & 0.12 & 0.064 \\
\hline
\end{tabular}

Many previous studies showed that the mechanical properties were closely related to the printing orientation of the sintering parts by SLS, especially the tensile properties. The tensile strength and elongation of the horizontally printed samples (built at $0^{\circ}(\mathrm{Z})$ ) are higher than those in other orientations [17]. Therefore, the horizontal sintering test as shown in Fig. 1 is selected in this study, that is, the length direction of all samples is perpendicular to the stacking direction. by Auspack-und Siebstation P1/P3 sieving machine of EOS to obtain uniform size. Fillers were added to PA2200 in 0,15 , and $30 \% \mathrm{w} / \mathrm{w}$ ratios. PA2200/HGB composites were mixing and grinding for 10-12 hours at a rotating speed of 1000-1200 R/min in the XHS-50KG high-speed mixer of Ningbo Beilun Tongsheng Machinery Manufacturing Company. Three kinds of PA2200/HGM composites, containing 0,15 and 30 wt.\% HGM respectively, were used. Hereafter, these materials are referred to as PA2200, $\mathrm{PH}-1$ and $\mathrm{PH}-2$, respectively.

All of the specimens tested were manufactured through the Selective Laser Sintering (SLS) process in an EOS P396 Machine: continuous wave $\mathrm{CO}_{2}$ laser with maximum power of $55 \mathrm{~W}$, wavelength of $10.6 \mu \mathrm{m}$, laser spot diameter of $0.4 \mathrm{~mm}$, vibration mirror type laser scanning system, maximum scanning speed of $5000 \mathrm{~mm} / \mathrm{s}$, working cabin size of $340 \times 340 \times 600 \mathrm{~mm}$, powder feeding mode of double cylinder.

As is well known, the sintering process parameters in SLS significantly influence the geometry and mechanical properties of the outcoming samples. According to the previous research [13], the preparation process parameters of the neat PA2200 are determined as shown in Table 1. Many researchers pointed that the filler act as a nucleus, while the crystallisation temperature is reached to higher temperatures [14-16]. Hence, we introduced the concept of energy density (ED), that was built by the power of the laser beam (P), velocity (v) and scan spacing (d), according to the following equations (1). Thus, it is necessary to apply higher energy density values and processing temperatures for composites. The sintering process parameters used for the entire samples are presented in Table 1 .

$$
E D=\frac{\mathrm{P}}{\mathrm{v} \cdot \mathrm{d}}\left[\mathrm{J} / \mathrm{mm}^{2}\right]
$$

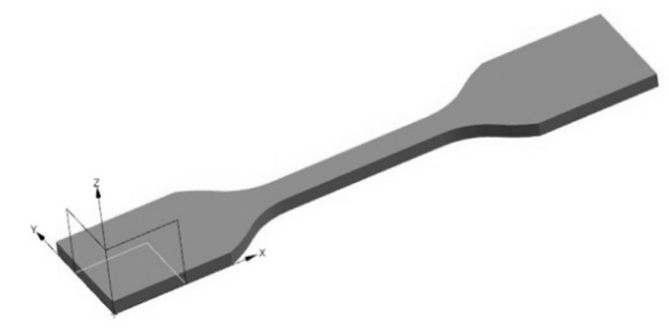

Fig. 1. Arrangement of specimens on SLS build platform. 


\subsection{Test Methods}

The tensile strength, tensile modulus, and elongation at break of the sintered parts were tested by UTM-1422 electronic universal testing machine according to ASTM D638 Standard as shown in Fig. 2. The particle size and distribution of composite powder were measured by Mastersizer 3000 laser particle size analyzer. Differential Scanning Calorimetry (DSC) measurements were performed using NETZSCH STA449F3 equipment and software. Samples with masses of $12.0 \pm 0.5 \mathrm{mg}$ were heated from $25^{\circ} \mathrm{C}$ to $250^{\circ} \mathrm{C}$ at a rate of $10^{\circ} \mathrm{C} / \mathrm{min}$, followed by a cooling ramp at $10^{\circ} \mathrm{C} / \mathrm{min}$ from $250^{\circ} \mathrm{C}$ to $25^{\circ} \mathrm{C}$. Two heating/cooling scans were undertaken subsequently. The morphology of composite powder and the fracture of the tensile sample were observed by ZEISS EVO 18 scanning electron microscope (SEM).

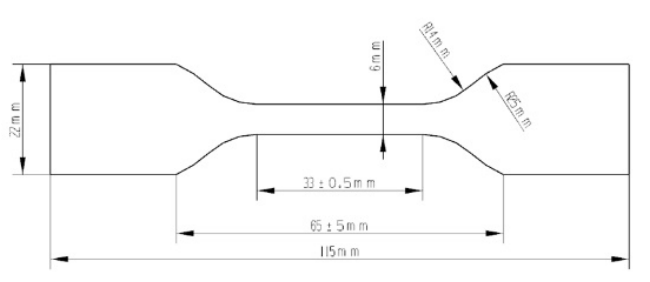

Fig. 2. Dimensions of the tensile test specimen as per ASTM D638.

\section{Results and discussion}

\subsection{The particle size distributions and the density}

The particle size distributions of three kinds of polyamide composites obtained by sieve analysis are shown in Table 2 . The data indicated that a large number of small particles are irregularly distributed around the large particles of polyamide powder. The powders of $\mathrm{PH}-1$ and $\mathrm{PH}-2$ are nearly spherical, and have good flow performance by adding the hollow spherical glass microsphere. That is good for spreading power. The particle size distributions of PH-1 and PH-2 are in the range of $12 \sim 180 \mu \mathrm{m}$, and

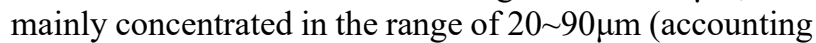
for more than 90\%). D10, D50 and D90 refer to the corresponding particle size that the cumulative distribution percentage reaches $10 \%, 50 \%$ and $90 \%$, respectively. $D[4,3]$ is the volume average diameter, and $\mathrm{D}[3,2]$ is the surface area average diameter. It can be seen that the median diameters of three powders are $58.7 \mu \mathrm{m}$, $50.1 \mu \mathrm{m}$ and $47.6 \mu \mathrm{m}$, the volume average diameters are $62.6 \mu \mathrm{m}, 53.9 \mu \mathrm{m}$ and $48.2 \mu \mathrm{m}$, and the values of $\mathrm{D}[3,2]$ and $\mathrm{D}[4,3]$ are relatively close. Therefore, three materials have particle sizes in the preferred range for SLS processing.
Table 2. The particle size distribution parameters of polyamide composite powder

\begin{tabular}{|c|c|c|c|c|c|}
\hline \multirow{2}{*}{ Material } & \multicolumn{5}{|c|}{ The parameters of the particle size } \\
& \multicolumn{5}{|c|}{ distribution/ $\mathbf{\mu m}$} \\
\cline { 2 - 6 } & $\mathbf{D 1 0}$ & D50 & D90 & $\mathbf{D}[\mathbf{4 , 3}]$ & $\mathbf{D}[\mathbf{3 , 2}]$ \\
\hline PA2200 & 33.2 & 58.7 & 114.2 & 62.6 & 48.1 \\
\hline PH-1 & 25.6 & 50.1 & 93.3 & 53.9 & 42.3 \\
\hline PH-2 & 20.3 & 47.6 & 87.4 & 48.2 & 37.9 \\
\hline
\end{tabular}

After sintering by SLS, compared with the neat PA2200, the density is significantly decreased to 0.903 $\mathrm{g} / \mathrm{cm}^{3}$ and $0.812 \mathrm{~g} / \mathrm{cm}^{3}$ in PH-1 and PH-2, respectively by introduction of $15 \mathrm{wt} . \%$ and $30 \mathrm{wt} . \%$ HGM to PA2200 due to the hollow structure of HGM as shown in Table 3. During the printing process by SLS, we can observe that mixing HGM into PA2200 can greatly improve the distortion of shrinking and bending.

\subsection{Thermal characterization}

Regarding the thermal information obtained from DSC analysis, Table 3 shows a single melting peak, Tm, around $185^{\circ} \mathrm{C}$ belonging to the $\gamma$-crystal phase of polyamide [18] for the three materials. Similarly, the crystallization peak, Tc, coincided at $\sim 140^{\circ} \mathrm{C}$ for all materials. The sintering window, defined as the difference between endothermic and exothermic peak temperatures, ranged around $40^{\circ} \mathrm{C}$ for the two composites, asseverating the suitability of PH1 and PH-2 for the SLS process. Tm and Tc values are increased when HGM content rises, especially at $30 \%$ of HGM addition. The crystalline degree was smaller in the composite than in the neat PA2200 because the hard particles induce heterogeneous nucleation and more imperfections acting in detriment of crystallinity.

Table 3. Thermal properties of the tested materials obtained from DSC analysis.

\begin{tabular}{|c|c|c|c|c|}
\hline Material & $\begin{array}{c}\text { Filler } \\
\text { content(\%) }\end{array}$ & $\mathbf{T c}\left({ }^{\circ} \mathbf{C}\right)$ & $\mathbf{T m}\left({ }^{\circ} \mathbf{C}\right)$ & $\begin{array}{c}\text { Density } \\
\left(\mathbf{g} / \mathbf{c m}^{3}\right)\end{array}$ \\
\hline PA2200 & 0 & 139.8 & 185.3 & 0.951 \\
\hline PH-1 & 15 & 142.4 & 187.2 & 0.903 \\
\hline PH-2 & 30 & 146.2 & 192.0 & 0.812 \\
\hline
\end{tabular}

\subsection{Tensile results}

The evolution of the tensile strength, the tensile modulus and the elongation at break of the three samples is shown in Fig. 3. Firstly, it is necessary to say that the results of the tensile test are in accordance with those reported by other authors for the neat PA2200 [16,18]. Secondly, it is clear that the tensile modulus of PH-1 and PH-2 are much higher than that of neat PA2200. As Fig. 3 shows, the neat PA2200 has the highest tensile strength and the best ductility, which are $47.63 \mathrm{MPa}$ and $17.56 \%$, respectively. On the whole, although the tensile strength and elongation at break of PH-1 and PH-2 are slightly lower than those of neat PA2200, tensile modulus increases by the increasing content of HGM addition and reaches to $2935.16 \mathrm{MPa}$ of PH-2.

Concerning the effect on the reinforcement of HGM, it is conducive to the elastic properties with an increase in the tensile modulus. Nevertheless other properties such as 
the tensile strength and the elongation at break are negatively affected, especially at $30 \%$ of HGM addition. Although the average tensile strength of the PH-1 sample was lower than that of neat PA2200 sample, the maximum value was higher. The observed unexpected differences are related to the treatment of HGM by silane coupling agent, where the adhesion between the filler and the PA 2200 matrix play a critical role.
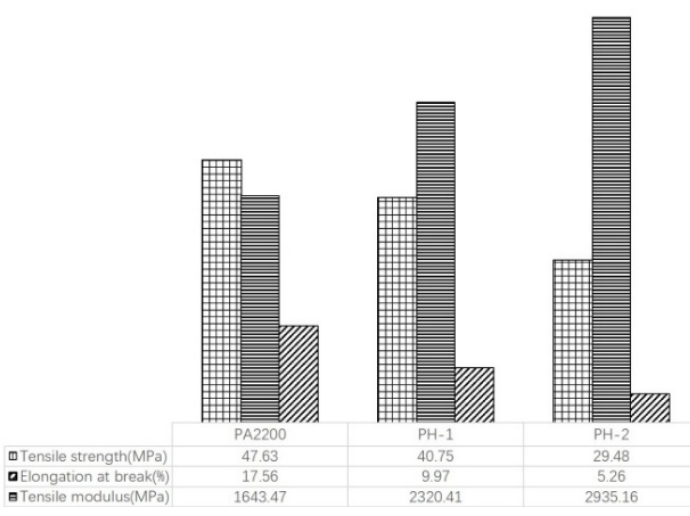

Fig. 3. The tensile test results of PA2200, PH-1 and PH-2.

\subsection{Morphology Observation of fracture surface}
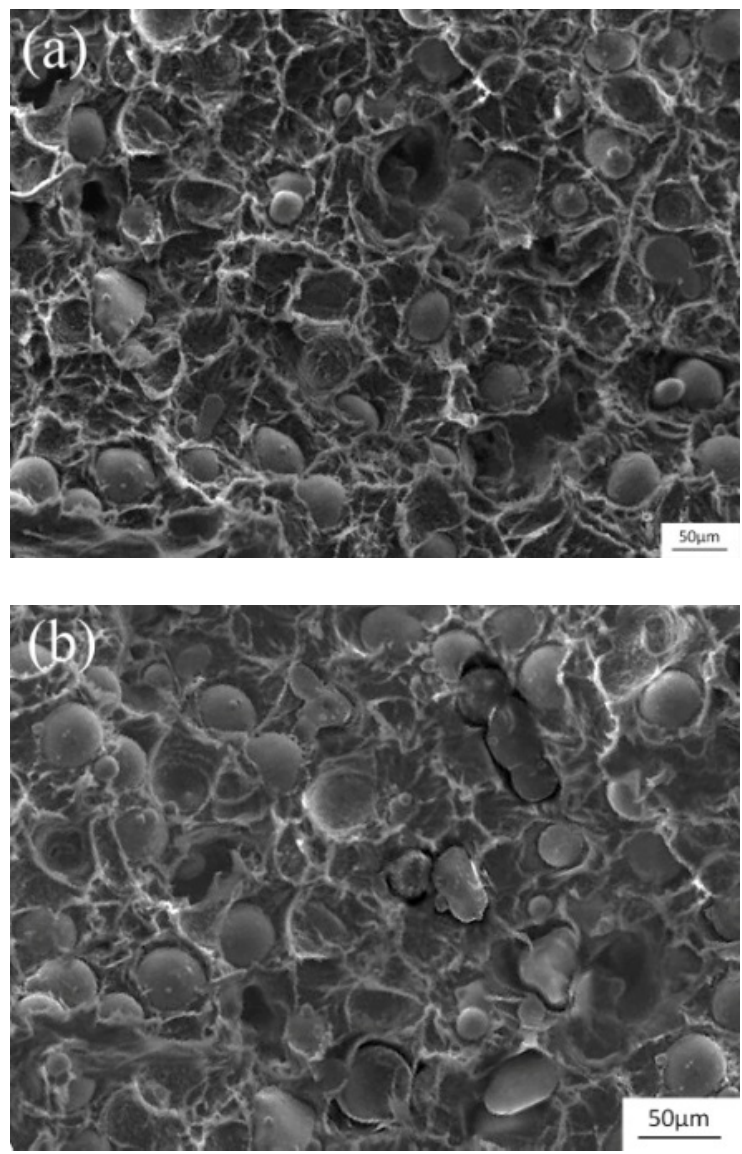

Fig. 4. SEM images of fracture surfaces of (a) PH-1 and (b) PH-2

The SEM analysis performed on the fracture surfaces of PH-1 and PH-2 are displayed in Fig. 4. It can be clearly seen that HGMs are homogeneously mixed in the polyamide matrix, while some HGMs are no longer spherical shape because of melting deformation. The fracture surfaces are generally quite plain, which indicated PA2200 matrix and HGM have a good interaction. Due to the fracture behavior was controlled by microstructural defects, the reduction in tensile strength and elongation values of $\mathrm{PH}-1$ and $\mathrm{PH}-2$ could be caused by small voids (porosities) in the structure[16]. There is no significant reinforcement strengthening effect has been detected, depending on the further improvement of the adhesion between the hollow glass microsphere and the matrix.

\section{Conclusions}

The effect of adding HGM prepared by silane coupling agent surface treatment on the sintering process, microstructure, thermal and mechanical properties of PA2200 were experimentally analyzed. It was found that HGM can improve the spreading power and the warping deformation during the sintering process by SLS. With increasing the content of HGM, the density of composite significantly reduced. HGM played a key role on light weighting for polyamide composite. The increasing content of HGM in PA2200 caused the increase of crystallisation temperature and crystallisation ratios. The tensile modulus increased while the tensile strength and elongation at break decreases as a function of HGM volume fraction in a certain range. PA2200 matrix and HGM have a good interaction. The results show that the addition of HGMS has the potential to prepare lightweight, high-performance and low-cost polyamide composite parts.

\section{Acknowledgement}

This work was supported by Science and Technology Research Project of Hubei Education DepartmentGuidance Project (B2019401 and B2020384).

\section{References}

1. E.C. Hofland, B. Ismet, D.A. Wismeijer, Adv. Mater. Sci. Eng. 2017, 1 (2017)

2. W.S. Chow, Express Polym. Lett. 9, 211 (2015)

3. D.L. Francisco, L.B. Paiva, W. Aldeia, Polym. Compos. 40, 851(2019)

4. M.K. Akkapeddi, Polym. Compos. 4, 576 (2000)

5. M. Palumbo, G. Donzella, E. Tempesti, P. Ferruti, J. Appl. Polym. Sci. 1, 47 (1996)

6. G. Anbuchezhiyan, B. Mohan, D. Sathianarayanan, T. Muthuramalingam, J. Alloys Compd. 719, 125(2017)

7. D. Lehmhus, J.Weise, J. Baumeister; L. Peroni, M. Scapin, C. Fichera, M. Avalle, M. Busse, Procedia Mater. Sci. 4, 383 (2014)

8. X.J. Ding, D.M. Lu, D.S. Yu, Plastics, 32, 19 (2003) (in Chinese)

9. X.D. Sun, Appl. Eng. Plastics, 1, 7 (2005) (in Chinese)

10. J.H. Wang, E.P. Bai, B. Liu, China Mechanical Eng. 1, 239 (2006) (in Chinese) 
11. B. Wang, C. Huang, Z. Huang, J. Zhang, Chinese J. Mater. Res. 30, 209 (2016)

12. Y.B. Guo, Z. Zhang, Z.Q. Cao, D.G. Wang, Mater. Today Commun. 29, 366 (2019)

13. G. Hou, H. Zhu, D. Xie, IOP Conference Series: Earth and Environmental Science, 571, 012111 (2020)

14. S. Negi, R.K. Sharma, S. Dhiman, Adv. Manuf. Process. 30, 644 (2015)

15. L. Lydia, W. Katrin, G. Sandra, D. Dietmar, Polym. Compos. 40, 1801 (2019)

16. B. Zbay, E.I. Serhatli, Mater. Technol. 1, (2020)

17. L. Shamieh, N.M. Popa, N.L. Milodin, C. Stanca, D. Gheorghiu, MATEC Web of Conferences, 299, 01001 (2019)

18. H. Zarringhalam, N. Hopkinson, N.F. Kamperman, J. Vlieger, Mat. Sci. Eng. A - Struct. 435-436, 172 (2006) 